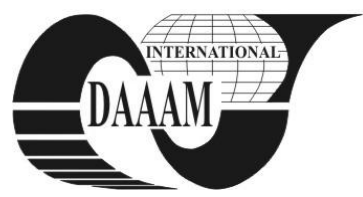

Annals of DAAAM for 2011 \& Proceedings of the 22nd International DAAAM Symposium, Volume 22, No. 1, ISSN 1726-9679 ISBN 978-3-901509-83-4, Editor B. Katalinic, Published by DAAAM International, Vienna, Austria, EU, 2011 Make Harmony between Technology and Nature, and Your Mind will Fly Free as a Bird

\title{
ROBUSTNESS ANALYSIS OF PMSM LPV CONTROLLER
}

\author{
POHL, L[ukas] \& VESELY, L[ibor]
}

\begin{abstract}
This paper presents robustness analysis of linear parameter varying (LPV) controller for permanent magnet synchronous motor (PMSM). Robust controller was designed for synchronous motor in $d-q$ rotating frame. Nonlinear equations of PMSM were rewritten to an LPV form with rotor speed as varying parameter. $H_{\infty} L P V$ Controller was designed using Matlab Robust Control Toolbox. Desired shapes of sensitivity and complementary sensitivity functions were specified by weighting functions. Simulations with nonlinear model of PMSM were run with different sets of rotor resistance in order to verify robustness of resulting controller.
\end{abstract}

Key words: PMSM, LPV, robust control, $H_{\infty}$

\section{INTRODUCTION}

Nonlinear equations commonly used in current control techniques are usually treated in two different ways, both based on the linearization of motor equations. First approach uses Taylor Series expansion of a function around some point of interest. Second approach uses exact linearization to find substitute which will make the motor equations linear and controllable.

Linear parameter varying (LPV) method described in this article will provide linear state space equations which will require only rotor speed to be known. Additionally $\mathrm{H}_{\infty}$ control technique provides means to design closed-loop properties to achieve desired behavior such as size and shape of robust stability, control effort and target accuracy. This method was successfully used in (Prempain, 2002) for control of an AC induction motor. Goal of this paper is to modify controller from (Pohl, 2011) to be usable in real world application and verify its performance and robustness for different sets of conditions.

\section{PMSM AS LPV SYSTEM}

LPV system can be described by state space equations of the following form:

$$
\begin{aligned}
& \dot{x}=A(\omega(t)) x+B(\omega(t)) u \\
& y=C(\omega(t)) x+D(\omega(t)) u
\end{aligned}
$$

PMS motor d-q equations are rewritten to this LPV form:

$$
\begin{gathered}
\dot{x}=\left(A_{1} \alpha_{1}+A_{2} \alpha_{2}\right) x+\left(B_{1} \alpha_{1}+B_{2} \alpha_{2}\right) u \\
y=C x+D u
\end{gathered}
$$

Where $\dot{x}=\left[\dot{l}_{d}, i_{q}\right]^{T}$ represents $\mathrm{d}$-q stator currents, $u=$ $\left[u_{d}, u_{q}, \Phi_{f}\right]^{T}$ are the control inputs and $y=\left[i_{d}, i_{q}\right]^{T}$ are the controlled outputs. Uncertain parameters $\alpha_{1}, \alpha_{2} \geq 0, \alpha_{1}+\alpha_{2}=$ 1 are defining current position between the vertices of parameter dependent system composed of following system matrices:

$$
\begin{gathered}
A_{1}=\left[\begin{array}{cc}
-a_{1} & \omega_{\min } a_{3} \\
-\omega_{\min } a_{4} & -a_{2}
\end{array}\right] \\
A_{2}=\left[\begin{array}{cc}
-a_{1} & \omega_{\max } a_{3} \\
-\omega_{\max } a_{4} & -a_{2}
\end{array}\right] \\
B_{1}=\left[\begin{array}{ccc}
0 & a_{5} & 0 \\
\omega_{\min } a_{6} & 0 & a_{6}
\end{array}\right] \\
B_{2}=\left[\begin{array}{ccc}
0 & a_{5} & 0 \\
\omega_{\max } a_{6} & 0 & a_{6}
\end{array}\right] \\
C=\left[\begin{array}{ll}
1 & 0 \\
0 & 1
\end{array}\right] D=\left[\begin{array}{lll}
0 & 0 & 0 \\
0 & 0 & 0
\end{array}\right]
\end{gathered}
$$

Following substitutions were made:

$$
\begin{gathered}
a_{1}=\frac{R_{s}}{L_{d}}, a_{2}=\frac{R_{s}}{L_{q}}, a_{3}=\frac{L_{q}}{L_{d}}, a_{4}=\frac{L_{d}}{L_{q}} \\
a_{5}=\frac{1}{L_{d}}, a_{6}=\frac{1}{L_{q}}
\end{gathered}
$$

Situation when we use LPV controller to control nonlinear plant where controllers varying parameter is obtained from the plant itself (by measurement or estimation) is shown in Fig. 1.

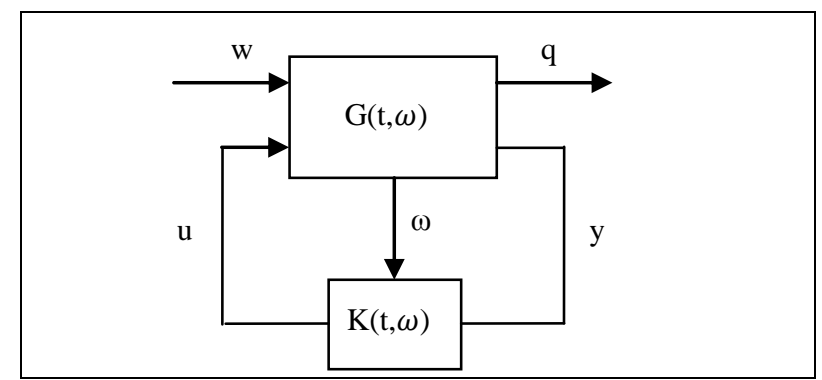

Fig. 1. LPV control structure

The goal is to design controller for this plant which guarantees quadratic $\mathrm{H}_{\infty}$ performance for the closed-loop system and quadratically stabilizes the closed-loop system from $\mathrm{w}$ to $\mathrm{q}$ bounded by $\gamma$ for all possible trajectories of $\omega$ (Apkarian, 1994).

\section{WEIGHT SELECTION}

It is possible to specify desired closed loop performance using weighting functions. Position of weighting function in closed loop system will affect the shape of each related system function. Each system function represents one property of conventional closed loop system (Patra, 2011), for example $(I+G K)^{-1}$ is sensitivity function and it relates to disturbance rejection. Its counterpart the complementary sensitivity function $G K(I+G K)^{-1}$ relates to tracking performance. In order to track the control effort we can use function mapping inputs to actuating variable $G(I+G K)^{-1}$. Following weighted 
system functions were considered for $\mathrm{H}_{\infty}$ loop shaping of LPV current controller (Roche, 2009):

$$
\left\|\begin{array}{cc}
W_{e} & S \\
W_{y} & T \\
W_{u} & G S
\end{array}\right\|_{\infty}<\gamma
$$

Weights were selected using following criteria:

$$
\frac{1}{W_{e}}=\frac{s+\omega_{b} A}{\frac{1}{M} s+\omega_{b}}
$$

With $\mathrm{M}=2$ for robust stability of $0.5, \mathrm{~A}=0.01$ for tracking error less than $1 \%$ and $\omega_{\mathrm{b}}=500$ for having a response time of 5 seconds. All other weights were selected as static gain with values $W_{y}=0.9$ (overshot limited to $11 \%$ ) and $W_{u}=0.001$ (control limit of 60dB).

Achieved closed-loop quadratic $\mathrm{H}_{\infty}$ performance $\gamma$ with weights defined above was 1.07 .

\section{CLOSED LOOP SIMULATIONS}

In order to simulate controller's behavior as close to real word conditions as possible several changes were made to original speed controller simulation. Original speed controller was not limiting the control action (current) entering the current loop as desired current. This resulted in large control actions over a $100 \mathrm{~A}$.

Changes to controlled plant were made for the speed controller simulations. PMSM stator resistance was changed prior to the simulation to values of $60 \%$ and $140 \%$ of the nominal value (Tab. 1).

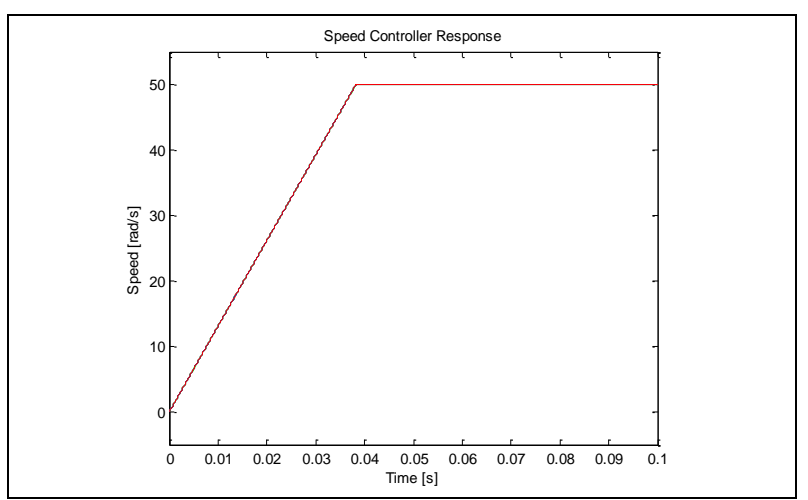

Fig. 2. Speed controller response for $+/-40 \%$ changes in stator resistance

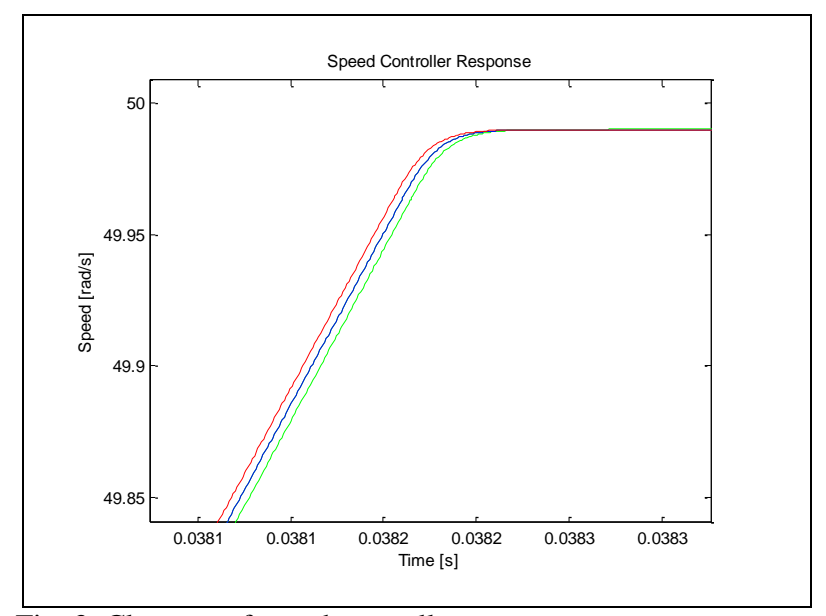

Fig. 3. Close-up of speed controller response

\section{CONCLUSION}

This paper presented analysis of robust controller with limited control action. Performance and robustness were tested on PMSM nonlinear model where nominal values of stator resistance were changed to two corner values of $+/-40 \%$ nominal resistance. Assumptions from (Pohl, 2011) were confirmed and robust controller was able to provide stable control without sacrificing its performance, in fact the current closed loop as seen in figures 2 and 3 is not sensitive to $40 \%$ changes in stator speed at all (difference in response can be spotted on close up in Fig. 3). Limit of the control action was implemented by current saturation. Impact of this limitation is that the rotor speed increases almost linearly to the desired value - it is because the response of current loop is significantly quicker than of the outer speed loop. Plan for future improvement is that the speed of the inner current loop needs to be decreased in order to lower the gains in controller's state matrices (now the maximum values are at $10^{7}$ ). This can be achieved by modifying the sensitivity function weight, allowing slower controller response.

\section{ACKNOWLEDGMENT}

The research has been supported by Czech Science Foundation under the project GA P103/10/0647 "Intelligent Electrical Drives Predictive and Robust Control Algorithms", the Ministry of Education of the Czech Republic under the project 1M0567 "Center for Applied Cybernetics".

\section{TABLES}

All simulations were run with following nominal parameters:

\begin{tabular}{|l|l|}
\hline Description & Value \\
\hline Direct axis inductance $\mathrm{L}_{\mathrm{d}}$ & $0.00129 \mathrm{H}$ \\
\hline Quadrature axis inductance $\mathrm{L}_{\mathrm{q}}$ & $0.00129 \mathrm{H}$ \\
\hline Stator resistance $\mathrm{R}_{\mathrm{s}}$ & $0.14 \Omega$ \\
\hline Rotor flux $\Phi_{\mathrm{f}}$ & $0.378 \mathrm{~Wb}$ \\
\hline Moment of inertia $\mathrm{J}_{\mathrm{m}}$ & $0.0104 \mathrm{~kg} \cdot \mathrm{m}^{2}$ \\
\hline Number of pole pairs $\mathrm{p}$ & 3 \\
\hline
\end{tabular}

Tab. 1. PMSM nominal parameters

\section{REFERENCES}

Prempain, E.; Postlethwaite, I. \& Benchaib, A. (2002). A linear parameter variant $H_{\infty}$ control design for an induction motor. Control Engineering Practice 10 633-644

Patra, S.; Sen, S. \& Ray, G. (2011). Design of $H_{\infty}$ LoopShaping Controller for LTI System With Input Saturation: Polytopic Gain Scheduled Approach. Journal of DynamicSystems, Measurement and Control, Vol. 133, January 2011

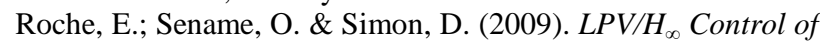
an Autonomous Underwater Vehicle (AUV). European Control Conference ECC'09, Budapest, Hungary, August 2009

Skogestad, S. \& Postlethwaite, I. (2001). Multivariable Feedback Control. August 2001

Apkarian, P.; Gahinet, P. \& Becker, G. (1994). Self-Scheduled $H_{\infty}$ Control of Linear Parameter-Varying System. American Control Conference Baltimore, Maryland, June 1994

Pohl, L. \& Blaha, P. (2011). Linear Parameter Varying Approach to Robust Control of a Permanent Magnet Synchronous Motor, Intelligent Engineering Systems (INES), June 2011 